\title{
Tolvaptan for hyponatremia with preserved sodium pool in critically ill patients
}

\author{
Michele Umbrello ${ }^{1,2^{*}}$, Elena S. Mantovani ${ }^{1}$, Paolo Formenti ${ }^{1}$, Claudia Casiraghi ${ }^{2}$, Davide Ottolina ${ }^{2}$, \\ Martina Taverna ${ }^{2}$, Angelo Pezzi ${ }^{1}$, Giovanni Mistraletti ${ }^{1,2}$ and Gaetano lapichino ${ }^{1,2}$
}

\begin{abstract}
Background: Hyponatremia is the most common electrolyte disturbance in hospitalized patients, and it represents a well-established risk factor for ICU/hospital mortality. The majority of hyponatremic states are associated with elevated arginine vasopressin levels and a preserved sodium pool. Conventional treatment is either not pathophysiologically oriented or of limited effectiveness. The aim of the present study is to investigate the use of enteral Tolvaptan in critically ill hyponatremic patients.
\end{abstract}

Methods: This is a retrospective observational study in a general ICU. Patients with preserved sodium pool hyponatremia refractory to conventional therapy were enrolled. The hemodynamic, renal, and hepatic functions, together with sodium and water balance as close as possible to the drug administration and up to $72 \mathrm{~h}$ thereafter, were analyzed. The main outcome was a serum sodium increase of $\geq 4 \mathrm{mmol} / \mathrm{L}$ in $24 \mathrm{~h}$; secondary endpoints were the ability to maintain serum sodium at 24 and $72 \mathrm{~h}$, a decrease in urine sodium concentration and an increase in sodium-free diuresis.

Results: 38 patients were enrolled. The average dose of enteral Tolvaptan was $7.5 \mathrm{mg} .31$ patients (81.6\%) increased their serum sodium $>4 \mathrm{mmol} / \mathrm{l} / 24 \mathrm{~h}$; the average increase was $6.7 \pm 3.4 \mathrm{mmol} / \mathrm{l}$ during the first $24 \mathrm{~h}(p<0.001 \mathrm{vs}$ baseline), and this was sustained at $72 \mathrm{~h}$. No adverse effects were reported. Plasma sodium $(R=-0.622, p<0.001)$, urine sodium $(R=-0.345, p<0.001)$, central venous oxygen saturation $(R=0.401, p=0.013)$, and BUN $(R=-0.416$, $p=0.031)$ before Tolvaptan were all significantly correlated with the absolute increase in serum sodium after the administration.

Conclusions: Enteral administration of Tolvaptan seems effective in the treatment of hyponatremia with preserved sodium pool in critically ill patients. Even if the study was underpowered to detect significant side effects or complications of unwarranted fast corrections of hyponatremia, we report no complications.

Keywords: Hyponatremia, Critical illness, Tolvaptan

\section{Background}

In a large-scale epidemiologic study, hyponatremia (serum sodium concentration- $\left[\mathrm{Na}^{+}\right] \leq 135 \mathrm{mmol} / \mathrm{L}$ ) was present at admission in $14.5 \%$ of patients, and during hospitalization in an additional $5 \%$ [1]. The risk of

\footnotetext{
*Correspondence: michele.umbrello@fastwebnet.it

${ }^{1}$ Unità Operativa di Anestesia e Rianimazione, Azienda Ospedaliera San

Paolo-Polo Universitario, Via A. Di Rudinì, 8, 20142 Milan, Italy

Full list of author information is available at the end of the article
}

mortality in those patients is evident even in mild cases $\left(\left[\mathrm{Na}^{+}\right] 130-134 \mathrm{mEq} / \mathrm{L}\right)$, which constitute the majority of cases of hyponatremia, and the increased risk of death persists up to 5 years beyond discharge [1].

In the ICU, the prevalence of hyponatremia on admission is around $15-20 \%[2,3]$; moreover, among patients with normal $\left[\mathrm{Na}^{+}\right]$at admission, a first episode of ICUacquired hyponatraemia develops in $11 \%$ of cases [4]. Independent of the severity of the underlying disease, both hyponatremia at admission and ICU-acquired 
hyponatremia are significantly related to ICU and hospital mortality. Similar associations with mortality result from the duration of sodium disturbances [3, 4]. Correction of acute and severe hyponatremia is lifesaving; however, despite the widespread clinical impression that correction of less severe hyponatremia is also worthwhile, evidence-based data demonstrating clinical benefit are limited [5].

$\left[\mathrm{Na}^{+}\right]$represents the ratio of total body sodium pool to total body water pool [6]. Depending on total body sodium stores, hyponatremia can be hypovolemic, normovolemic, or hypervolemic, with body sodium pool reduced, preserved, or increased, respectively. However, the majority of hyponatremic states in critical illness are frequently non-hypovolemic (e.g., syndrome of inappropriate antidiuresis-SIAD) [2] and likely associated to elevated plasma levels of arginine vasopressin (AVP) [7], due to an underlying cause of inappropriate antidiuresis [8]. AVP-induced water retention leads to increased body water pool and subsequent dilution of serum sodium [9, 10 ], with excess total body water relative to the preserved total body sodium pool [11].

The traditional approach to the treatment of such cases involves restriction of free water intake [12], use of loop diuretics [13], demeclocycline [14], osmotic diuretics, such as urea [15] or intravenous administration of normal or hypertonic saline [16]. In ICU patients, fluid restriction is in fact poorly tolerated and difficult to achieve [17], and increased intake of salt does not address the causative factor, which is free water excess.

Indeed, loop diuretics result in the excretion of urine with a lower sodium concentration than plasma (i.e., more water than sodium is excreted, as compared to plasma) [13]. The subsequent correction of hyponatremia would then occur at the expense of salt depletion. For this reason, it is generally recommended that a concomitant administration of both $\mathrm{NaCl}$ (as hypertonic saline) and furosemide is performed in hyponatremia with normal sodium pool [18]. In particular, this is the only effective approach in severe cases of hyponatremia (i.e., coma and or convulsions), because the effects of combined salt and furosemide are extremely rapid [11]. However, other complications besides the reduction in body sodium pool can be determined by loop diuretic administration, such as hypokalemia, hypochloremia, hypomagnesemia, metabolic alkalosis [19], and this explains why this treatment is generally reserved to the acute phases of correction only [20].

Urea is an osmotic diuretic, and it increases free water excretion according to each patient urine osmolality and the amount of drug administered. Despite recent positive report on its use in critically ill patients [21], clinical data with this drug are, however, limited; in addition, urea is not a receptor-targeted agent and it has been associated with potential side effects (azotemia, nausea/vomiting, allergic reactions, renal toxicity, hypernatremia, and/or hypokalemia) [21].

Vaptans are a recently introduced class of vasopressin V2-receptor antagonists, yielding to an increased electrolyte-free water excretion and, thus, increased serum sodium concentration [22]. Several studies showed their safety and effectiveness in hyponatremia with preserved total body sodium pool in different categories of patients [17, 23-27]; however, the experience with these drugs is limited in the critical care setting. After positive initial experience with oral Tolvaptan in single cases [28, 29], we sought to analyze our case series to investigate the shortterm outcomes on water and electrolyte balance for patients prescribed oral vaptans for hyponatremia with preserved total body sodium pool within our ICU.

\section{Methods}

Ethics, consent, and permission

The case series was conducted in a in a 6-bed general ICU of a University hospital. After obtaining approval from the Institutional Review Board ("Comitato Etico Interaziendale Milano Area A"-n. 16413), we enrolled patients treated with oral Tolvaptan between the date the drug was introduced into our clinical practice, January 2012, and January 2014. In all cases, decision to administer Tolvaptan was made by the physician in charge of the patient. Patients provided informed consent for the utilization of their data. All patient data have been anonymized.

\section{Data collection and inclusion criteria}

We performed a retrospective analysis of prospectively collected case series; patients were treated following a specific internal protocol for the management of hyponatremia, resulting in a heterogeneous population of critically ill patients in whom hyponatremia was treated homogeneously. The following inclusion criteria were used: (1) diagnosis of clinically significant hypoosmolar hyponatraemia $\left(\left[\mathrm{Na}^{+}\right] \leq 135 \mathrm{mmol} / \mathrm{L}\right.$ and serum osmolality $<280 \mathrm{mOsm} / \mathrm{kg}$ ) with raised urine osmolality (urine osmolality $>100 \mathrm{mOsm} / \mathrm{kg}$ and urine sodium $>20 \mathrm{mmol} / \mathrm{L}$ ) [30]; (2) no history of reduction in body sodium pool (i.e., diuretic use, gastrointestinal losses, hemorrhage, low sodium intake); (3) lack of clear signs of hypovolemia (i.e., tachycardia, pale, cold, and clammy skin, delayed capillary refill, hypotension, oliguria, hyperlactatemia, reduced central venous blood oxygen saturation); (4) the presence of a possible underlying cause of inappropriate antidiuresis (i.e., central nervous system disorder, pulmonary diseases, mechanical ventilation, drug-induced) [8]; and (5) failure to correct 
hyponatraemia (absolute increase in $\left[\mathrm{Na}^{+}\right] \geq 4 \mathrm{mmol} / \mathrm{L}$ over baseline) despite at least $24 \mathrm{~h}$ of free water restriction $(<1$ l); (6) age $>18$.

Given the limited experience with the drug in this class of patients and to avoid the risks of overcorrection, fluid restriction was only prescribed before the administration of Tolvaptan. As in case of serum sodium overcorrection, any saline infusion was temporarily withheld, and further correction from urinary free water losses was prevented by replacing losses with $5 \%$ dextrose in water [11]. The dose of Tolvaptan was not standardized as the decision on the dose to be administered was left to the attending intensivist. We performed a post hoc subgroup dividing patients by the dose they receive (either 7.5 or $15 \mathrm{mg}$ ).

Patients who were given Tolvaptan were identified from pharmacy records; we then retrieved their paper charts and analyzed their clinical course. The data collected included age, sex, diagnosis, ICU and hospital length of stay, dose and duration of Tolvaptan administration, Sequential Organ Failure Assessment (SOFA) score, ICU, and in-hospital mortality. Hemodynamic data including mean arterial pressure, heart rate, arterial lactate, base excess, rates of inotrope, and vasopressor infusions were recorded, as was 24-h urine output and the net fluid balance, the total amount of sodium administered and the daily sodium balance, the duration of hyponatremia prior to treatment and the day of Tolvaptan administration from ICU admission, serum and urine sodium and potassium at initiation of treatment and every $24 \mathrm{~h}$. Additional laboratory data included serum creatinine, blood urea nitrogen (BUN), liver function tests, albumin, and hemoglobin concentration. Osmolality in serum and urine was not formally measured, and it was calculated using a standard formula; only 17 patients had urinary nitrogen determinations. We thus decided to present two different pieces of information on urinary osmolality: on the one hand, we calculated urinary salt osmolality (i.e., twice the sum of urinary sodium and potassium), which was available in all patients; on the other hand, for the subgroup of patients in which this was available, we also calculated, with a standard formula, total urinary osmolality. Data were collected as close as possible to the drug administration, and up to $72 \mathrm{~h}$ thereafter where this was available. Adverse events including hypotension and excessive rise in sodium concentration were recorded.

\section{Outcomes}

The primary outcome was the efficacy of Tolvaptan in correcting hyponatremia, defined as the percentage of patients with an absolute increase in $\left[\mathrm{Na}^{+}\right] \geq 4 \mathrm{mmol} / \mathrm{L}$ over baseline at $24 \mathrm{~h}$ after administration of the drug. This was selected for consistency with previous reports of similar interventions [31-33]. Secondary outcomes included absolute increase in $\left[\mathrm{Na}^{+}\right]$at $24 \mathrm{~h}$, absolute increase of $\left[\mathrm{Na}^{+}\right]$at $72 \mathrm{~h}$, and absolute decrease in urine sodium concentration. Sodium-free water clearance was estimated from an established equation using urine volume and urine and serum sodium [34]. As a safety endpoint, the rate correction of hyponatremia was examined. A rapid correction was defined as any increase in $\left[\mathrm{Na}^{+}\right] \geq 12 \mathrm{mmol} / \mathrm{L}$ after $24 \mathrm{~h}$ [11]. We also searched for adverse reactions resulting from hypovolemia and increased diuresis such as hemodynamic compromise and effects on serum potassium and renal function. An exploratory analysis was also conducted, to assess possible pre-treatment variables that could predict the response to therapy.

\section{Statistical analysis}

Data are represented as mean values \pm standard deviation if variables are normally distributed (as assessed by Shapiro-Francia test), or median (interquartile range) if not. Due to the observational nature of the study in a field for which no data are available as for the expected effect size, we referred to a study in which a vaptan was administered to a population of non-critically ill patients with hyponatremia with preserved total body sodium pool [31] to estimate the power. In that study, the percentage of patients administered a vaptan vs. placebo who increased their $\left[\mathrm{Na}^{+}\right] \geq 4 \mathrm{mmol} / \mathrm{l}$ in $24 \mathrm{~h}$ was 58 vs. $11 \%$. Considering a similar effect size and since we enrolled 38 patients, our study yields a power of $80.4 \%$ with $\alpha=0.05$.

Paired Student's $t$ test, or the Wilcoxon signed-rank test, was used for the comparison of variables between baseline and $24 \mathrm{~h}$ after Tolvaptan administration. The time course of serum sodium over the first $72 \mathrm{~h}$ was studied with Friedman test with post hoc comparison test. The association between the absolute increase in $\left[\mathrm{Na}^{+}\right]$ over the first $24 \mathrm{~h}$ and possible predictors of the response was assessed by means of parametric or non-parametric correlation analysis.

Data were collected from the medical charts and stored in an electronic data abstraction form, using a Microsoft Excel 2010 spreadsheet (Microsoft Corporation, Redmond, Wash). Statistical analysis was performed with Stata/SE 12.0 (StataCorp, College Station, TX USA) statistical software. For all comparisons, $p<0.05$ was considered significant.

\section{Results}

\section{Demographics and outcome}

38 patients received enteral Tolvaptan. Demographics and clinical characteristics at ICU admission and at study enrollment, as well as ICU and hospital outcomes, are reported in Table 1 . Average $\left[\mathrm{Na}^{+}\right]$at ICU admission was 135 [131; 138] (range 113-148). Hyponatremia was 


Table 1 Patient demographics and clinical data at enroll-
ment

\begin{tabular}{ll}
\hline Age (years) & $53 \pm 15$ \\
Male sex & $24(63.1 \%)$ \\
Height (cm) & $170 \pm 9$ \\
Body weight (kg) & $76 \pm 21$ \\
Ideal body weight (kg) & $63 \pm 7$ \\
Body mass index (kg/m2) & $26 \pm 6$ \\
Simplified acute physiology score II & $26 \pm 12$ \\
Admission type & \\
Medical & $26(68.4 \%)$ \\
Surgical unscheduled & $12(31.6 \%)$ \\
Diagnosis & \\
Pneumonia & $12(31.6 \%)$ \\
Urosepsis & $6(15.8 \%)$ \\
Peritonitis & $5(13.2 \%)$ \\
TUR syndrome & $4(10.5 \%)$ \\
Acute pancreatitis & $3(7.9 \%)$ \\
Cardiogenic shock & $2(5.3 \%)$ \\
Drug abuse & $2(5.3 \%)$ \\
Meningitis & $2(5.3 \%)$ \\
Osteomyelitis & $1(2.6 \%)$ \\
Chest trauma & $1(2.6 \%)$ \\
SOFA score at enrollment & $3[1 ; 5]$ \\
Organ support at enrollment & \\
Mechanical ventilation & $38(100 \%)$ \\
Vasoactive therapy & $2(5.3 \%)$ \\
Worst SOFA score during ICU stay & $6(3 ; 8)$ \\
Length of ICU stay (days) & $14(6 ; 23)$ \\
HCU mortality & $7(18 \%)$ \\
Age (years) & $12(31 \%)$ \\
Male (sex) & $53 \pm 15$ \\
Height (cm) & $24(63.1 \%)$ \\
\hline
\end{tabular}

diagnosed on average on day $5[2,12]$ from ICU admission; nadir $\left[\mathrm{Na}^{+}\right]$was $132[131 ; 134]$. Tolvaptan was administered on day $8[4,13]$.

\section{Tolvaptan dosing, efficacy, and adverse effects}

The average dose of Tolvaptan administered was 7.5 [7.5; 15] mg enterally: 24 patients $(63 \%)$ received $7.5 \mathrm{mg}$, while the remaining $14(37 \%)$ received $15 \mathrm{mg}$. Additional file 1: Tables S1 and S2 summarize the results of the subgroup analysis according to the dose of Tolvaptan received. We did not find any relevant difference between patients receiving $7.5 \mathrm{vs.} 15 \mathrm{mg}$.

Thirty-one $(81.6 \%)$ patients met the criterion for successful response, defined as an absolute serum sodium increase $\geq 4 \mathrm{mmol} / \mathrm{L} 24 \mathrm{~h}$ after Tolvaptan administration. Table 2 shows the primary and secondary outcomes of the study.

\section{Table 2 Primary and secondary outcomes}

\begin{tabular}{|c|c|}
\hline \multicolumn{2}{|l|}{ Primary outcome } \\
\hline $\begin{array}{l}\geq 4 \mathrm{mmol} / \mathrm{l} \text { increase in serum sodium over baseline at } \\
24 \mathrm{~h}-\mathrm{n}(\%)\end{array}$ & $31 / 38(81.6 \%)$ \\
\hline \multicolumn{2}{|l|}{ Secondary outcomes } \\
\hline $\begin{array}{l}\text { Absolute increase in serum sodium over baseline at } \\
24 \mathrm{~h}-\mathrm{mmol} / \mathrm{l}\end{array}$ & $6.7 \pm 3.4$ \\
\hline $\begin{array}{l}\text { Absolute increase in serum sodium over baseline at } \\
72 \mathrm{~h}-\mathrm{mmol} / \mathrm{l}\end{array}$ & $5.5 \pm 3.7$ \\
\hline $\begin{array}{l}\text { Absolute reduction in urine sodium over baseline at } \\
24 \mathrm{~h}-\mathrm{mmol} / \mathrm{l}\end{array}$ & $-68.0 \pm 39.9$ \\
\hline $\begin{array}{l}\geq 12 \mathrm{mmol} / \mathrm{l} \text { increase in serum sodium over baseline at } \\
24 \mathrm{~h}-\mathrm{n}(\%)\end{array}$ & $4 / 38(10.5 \%)$ \\
\hline Average hourly increase in serum sodium $-\mathrm{mmol} / \mathrm{I}^{*} \mathrm{~h}$ & $0.28 \pm 0.14$ \\
\hline
\end{tabular}

Before fluid restriction, mean baseline $\left[\mathrm{Na}^{+}\right]$was 133 [131; 134] (range 113-135) mmol/L. After a $24 \mathrm{~h}$ trial of fluid restriction, it was 133 [132; 135] (range 114-135) $\mathrm{mmol} / \mathrm{L}(p=0.431)$, and increased to 138 [137; 141] (range $128-147) \mathrm{mmol} / \mathrm{L}$ at $24 \mathrm{~h}$ after administration of Tolvaptan $(p<0.001)$. Increase in $\left[\mathrm{Na}^{+}\right]$was sustained at 48 and $72 \mathrm{~h}$ after administration of Tolvaptan (139 [137; 140] (range 126-147) and 137 [135; 140] (range 133-143) $\mathrm{mmol} / \mathrm{L}$, respectively; $p<0.001$ ). Fig 1 shows individual patient time course of serum sodium data. Table 3 shows the comparison of serum and urine electrolytes, sodium and fluid balance, hemodynamics, and liver and kidney function tests before and $24 \mathrm{~h}$ after administration of Tolvaptan. Fig 2 shows the changes in urine output and sodium-free water clearance observed before and $24 \mathrm{~h}$ after administration of Tolvaptan, as well as the change in serum and urine osmolality. No subsequent doses of Tolvaptan were administered. $\left[\mathrm{Na}^{+}\right]$at ICU discharge was 139 [136; 140].

Four patients (10.5\%) experienced rapid correction of hyponatraemia at $24 \mathrm{~h}$; all patients increased their serum sodium of $14 \mathrm{mEq} / \mathrm{L}$. All events were asymptomatic. No cases of hypokalemia or hyperkalemia occurred; 1 patient $(2.6 \%)$ developed mild hypernatremia $\left(\left[\mathrm{Na}^{+}\right]\right.$ $147 \mathrm{mEq} / \mathrm{L}$ ). No other adverse events were documented.

\section{Determinants of serum sodium increase}

Serum sodium $(R=-0.622, p<0.001)$, urine sodium $(R=-0.345, p<0.001)$, central venous blood oxygen saturation $(R=0.401, p=0.013)$, and $\mathrm{BUN}(R=-0.416$, $p=0.031$ ) before Tolvaptan administration were all significantly correlated with the absolute increase in $\left[\mathrm{Na}^{+}\right]$ $24 \mathrm{~h}$ after Tolvaptan administration.

\section{Discussion}

Maintenance of plasma osmolality and sodium concentrations within tight limits is one of the most highly regulated parameters of body physiology [35]; osmotically 


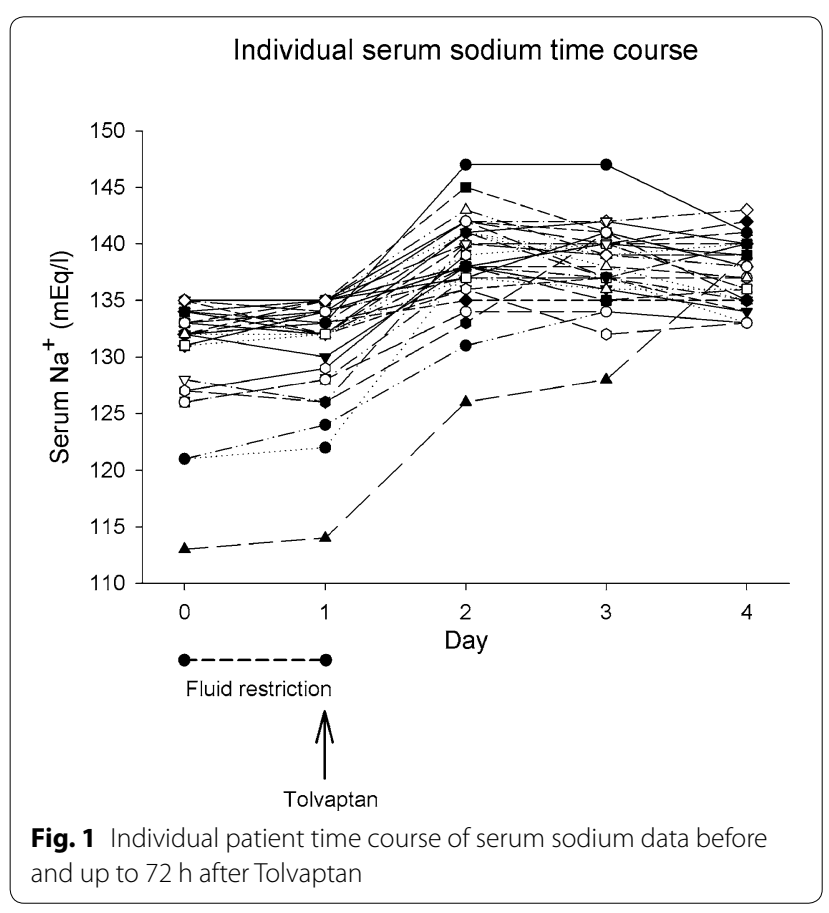

induced variations in cell volume can exert adverse effects on multiple cellular functions [36]. In virtually every disease state, the presence of hyponatremia was found to be an independent risk factor for increased mortality [11]. Indeed, a recent study in a large number of hospitalized hyponatremic patients proposed revising the definition of hyponatremia to $\left[\mathrm{Na}^{+}\right]<138 \mathrm{mmol} / \mathrm{L}$, because this was the level at which the association with increased mortality reached statistical significance [37].

Treating hyponatremia thus seems an important step in the management of patients, especially for the most critically ill. However, this entails choosing among several suboptimal therapies, i.e., fluid restriction, salt tablets, slow infusions of $3 \%$ saline, furosemide, and urea [6]. In cases of hyponatremia with preserved sodium pool, fluid restriction represents the cheapest, first-line treatment, despite the almost complete lack of a supportive evidence base [11]. The other associated therapeutic options, however, are represented by drugs with limited efficacy or a doubtful physiologic rationale, in that they mainly act on body sodium pool, while it is the water pool that is primarily altered. The recent development of

Table 3 Changes in electrolytes, hemodynamic, and biochemistry parameters before and after administration of Tolvaptan

\begin{tabular}{|c|c|c|c|}
\hline & Before & After & $P$ \\
\hline Serum sodium concentration $(\mathrm{mmol} / \mathrm{l})$ & $133[132 ; 135]$ & $138[137 ; 141]$ & $<0.001$ \\
\hline Urine sodium concentration (mmol/l) & $123.2 \pm 36.5$ & $54.9 \pm 5.4$ & $<0.001$ \\
\hline Serum potassium concentration $(\mathrm{mmol} / \mathrm{l})$ & $4.1 \pm 0.4$ & $4.2 \pm 0.3$ & 0.823 \\
\hline Urine potassium concentration $(\mathrm{mmol} / \mathrm{l})$ & $32.2 \pm 16.8$ & $24.8 \pm 15.1$ & 0.015 \\
\hline Urine output (ml/24 h) & $2149 \pm 966$ & $3593 \pm 1673$ & $<0.001$ \\
\hline Sodium input (mmol/24 h) & $159[111 ; 214]$ & $148[115 ; 169]$ & 0.824 \\
\hline Sodium balance (mmol/24 h) & $-69[143 ; 20]$ & $-49[-146 ; 37]$ & 0.789 \\
\hline Sodium output (mmol/24 h) & $236.5[120 ; 311]$ & $190.5[119.5 ; 298.5]$ & 0.654 \\
\hline Sodium-free water clearance (\%) & $9.6[-12.0 ; 24.4]$ & $59.9[43.3 ; 76.6]$ & $<0.001$ \\
\hline Fluid balance (ml/24 h) & $-200[-950 ; 0]$ & $-1300[-2200 ;-550]$ & $<0.001$ \\
\hline Heart rate $(1 / \mathrm{min})$ & $90.3 \pm 18.2$ & $92.1 \pm 20.4$ & 0.467 \\
\hline Mean arterial pressure $(\mathrm{mmHg})$ & $84.3 \pm 13.9$ & $82.7 \pm 11.0$ & 0.413 \\
\hline Central venous pressure $(\mathrm{mmHg})$ & $7.1 \pm 3.6$ & $6.1 \pm 4.1$ & 0.089 \\
\hline Patients on vasopressors & $1 / 38$ & $1 / 38$ & $>0.999$ \\
\hline Central venous oxygen saturation (\%) & $71.6 \pm 7.4$ & $70.9 \pm 7.2$ & 0.445 \\
\hline Albumin concentration (g/100 ml) & $2.3 \pm 0.3$ & $2.6 \pm 0.3$ & 0.015 \\
\hline Hemoglobin concentration (g/100 ml) & $10.6 \pm 2.0$ & $10.8 \pm 2.0$ & 0.098 \\
\hline Aspartate aminotransferase (IU/I) & $59 \pm 27$ & $49 \pm 22$ & 0.114 \\
\hline Alanine aminotransferase (IU/I) & $84 \pm 55$ & $80 \pm 56$ & 0.439 \\
\hline Bilirubin concentration (mg/100 ml) & $1.8 \pm 1.3$ & $1.9 \pm 1$ & 0.986 \\
\hline Serum creatinine concentration $(\mathrm{mg} / 100 \mathrm{ml})$ & $0.9 \pm 0.6$ & $0.8 \pm 0.5$ & 0.053 \\
\hline Blood urea nitrogen $(\mathrm{mg} / 100 \mathrm{ml})$ & $23.6 \pm 13.3$ & $20.1 \pm 11.5$ & 0.015 \\
\hline Serum lactate concentration $(\mathrm{mmol} / \mathrm{l})$ & $1.2 \pm 0.7$ & $1.0 \pm 0.4$ & 0.261 \\
\hline Serum glucose concentration (mg/100 ml) & $126 \pm 28$ & $120 \pm 21$ & 0.194 \\
\hline
\end{tabular}


the new pharmacologic approach of aquaresis-i.e., electrolyte-free water excretion - allows for removal of water not accompanied by elimination of sodium and other electrolytes [38].

Tolvaptan is an oral, competitive, selective vasopressin V2-receptor antagonist. It was shown to be effective in reversing hyponatremia with preserved total body sodium pool $\left(\left[\mathrm{Na}^{+}\right]<135 \mathrm{mmol} / \mathrm{L}\right)$ in the SALT- 1 and SALT-2 trials [24]. Pooled results for all patients showed changes in average daily serum sodium of $4.0 \mathrm{mmol} / \mathrm{L}$ vs $0.4 \mathrm{mmol} / \mathrm{L}$ for placebo at day 4 . A post hoc analysis of the phase III EVEREST trial demonstrated that patients hospitalized for heart failure with baseline hyponatremia who received Tolvaptan had an adjusted mean length of stay shorter compared with that for patients receiving placebo [25]. Tolvaptan was also shown to reduce hospital length of stay vs. placebo among patients with SIAD in the SALT-1 and -2 trials [39]. A recent meta-analysis on 11 trials (1094 patients) showed how the use of vaptans resulted in a $24-\mathrm{h}$ net increase in $\left[\mathrm{Na}^{+}\right]$of $3.3 \mathrm{mmol} / \mathrm{L}$ relative to the control group [17].

However, the published experience in current clinical practice and in patients not enrolled in randomized trials remains limited, particularly in the field of critical care medicine. Furthermore, clinical factors which can predict the extent of the response are not completely defined. The present investigation is one of the very few reporting experience of vaptans in critically ill patients, previous studies being case reports, or open label randomized studies assessing interest of Conivaptan in neuro-ICU patients with [40] or without [41] hyponatremia.

In this case series, we present a mixed cohort of critically ill patients who were either admitted to the ICU or developed during their stay a moderate hypotonic hyponatremia. The patients had no history of reduction in their total sodium pool, nor did they present any sign or symptom of overt hypovolemia (as evaluated by their values of hemodynamic parameters, urine output, blood lactate, $\mathrm{ScvO} 2$, skin perfusion); urine sodium was above the normal range. However, the average concentration of $10 \mathrm{~g} / 100 \mathrm{ml}$ hemoglobin associated with $23 \mathrm{~g} / \mathrm{l}$ albumin (Table 2), widely tolerated combination of hypoalbuminemia/anemia frequently seen in critically ill patients [42], might have contributed to the activation of AVP (given the altered circulating blood volume), besides the well-known factors (acute respiratory failure, pneumonia, trauma, mechanical ventilation, history of COPD) [8] that are nonetheless present in the case-mix.

After a trial of fluid restriction, Tolvaptan was administered enterally (via nasogastric tube) and, given the lack of previous experience with this drug in critically ill patients, we decided to use lower doses than generally used (on average, $7.5 \mathrm{mg}$ ). Even so, we report a rapid and effective response (average increase of $7 \mathrm{mmol} / \mathrm{l}$ in $24 \mathrm{~h}$ ) that nonetheless lasted up to $72 \mathrm{~h}$ after the first administration, again underscoring the feasibility of the enteral route for critically ill patients [43, 44]. Tolvaptan significantly increased $\left[\mathrm{Na}^{+}\right]$and reduced urine sodium, with no changes in either plasma or urine potassium. Moreover, sodium input and sodium balance were unchanged from before and after administration of the drug; still, urine output increased about $1.5 \mathrm{l}$, indicating free water diuresis (Fig. 2). The increased diuresis and the consequent negative fluid balance were not associated with any hemodynamic modification, nor did they induce hypoperfusion, again indicating the previously increased total body water pool and a likely osmotically driven reduction in the increased cell water content after administration of Tolvaptan. The decrease in urine $\left[\mathrm{Na}^{+}\right]$concentration was likely a dilutional effect of the increased urine water content, as total urine sodium output did not change significantly.

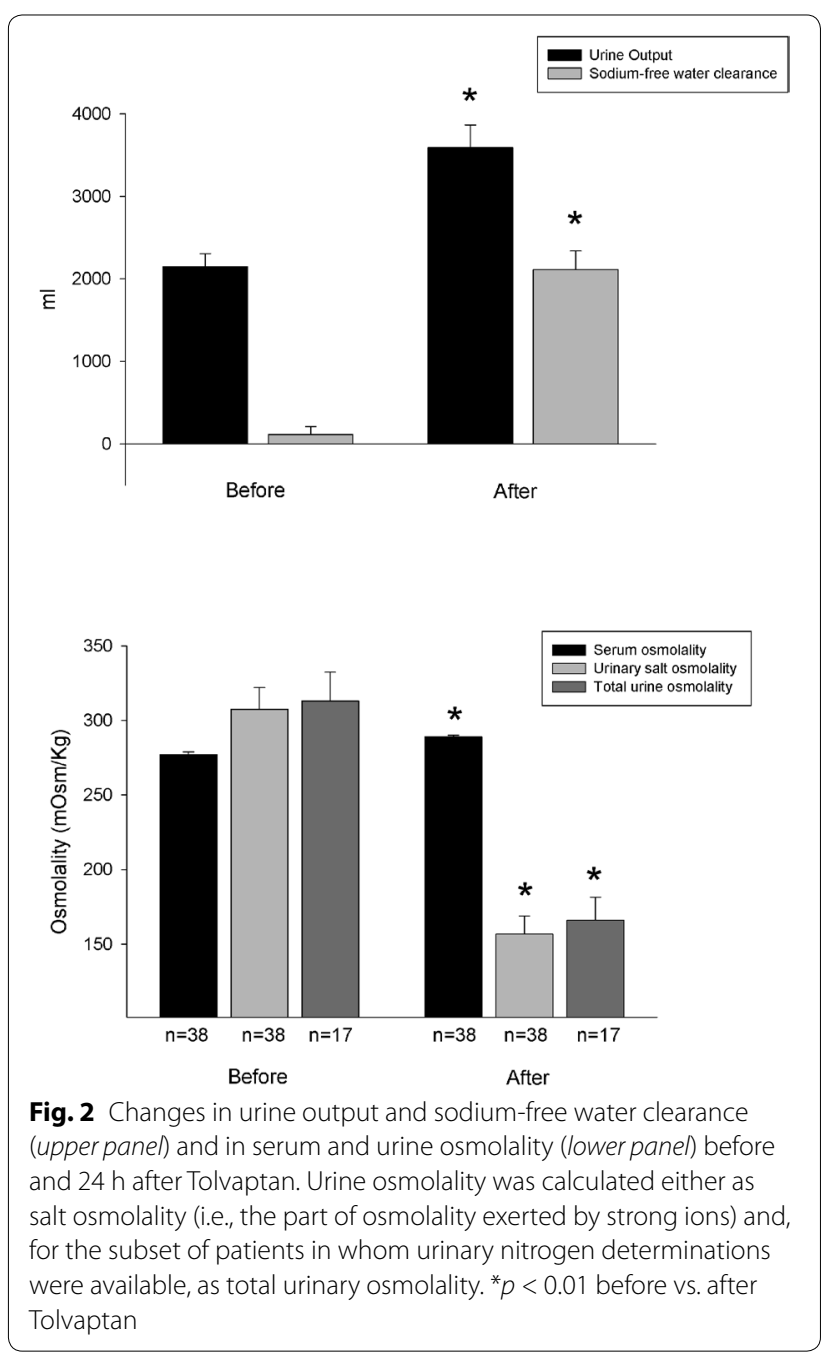


Only about $10 \%$ of patients experienced a daily increase in plasma sodium $>12 \mathrm{mmol} / \mathrm{l}$. Since overly rapid correction of hyponatremia risks iatrogenic brain damage, a 1-day increase of $12 \mathrm{mmol} / \mathrm{L} / \mathrm{d}$ is generally considered a safe threshold [11]. However, the risk of central pontine myelinolysis varies depending on several factors, and it is unlikely to occur if serum Na concentration is $>120 \mathrm{mEq} / \mathrm{L}$ [11]. One patient became mildly hypernatremic $(147 \mathrm{mEq} / \mathrm{L})$, and despite the fact that he developed no neurological symptoms, this should be acknowledged as development of hypernatremia is a risk factor for osmotic demyelination [11]. Indeed, none of these patients reported abnormalities to the neurologic examination, and particularly no cases of central pontine myelinolysis or any other severe neurological damage were seen. Moreover, this rate of correction is in line with other data on hyponatremia with preserved sodium pool in larger group of patients studied in the Hyponatremia Registry [5], or in patients treated with Tolvaptan [17], and lower than reported with the use of intravenous Conivaptan [33], thus suggesting a low prevalence of such side-effect with the low doses we used or a less drastic effect of enteral administration of the drug. We did not report any other relevant side-effect, and specifically, we did not see any short-term alteration in liver or kidney function tests.

We observed a certain degree of variability in the response to Tolvaptan administration. To better elucidate the potential mechanisms, and to possibly provide clinicians with predictors of the response to Tolvaptan, we searched for variables associated to the degree of the effect. As already reported [23, 33, 45], baseline $\left[\mathrm{Na}^{+}\right]$ was negatively associated with the subsequent rise in $\left[\mathrm{Na}^{+}\right]$resulting from treatment, i.e., the lower the baseline $\left[\mathrm{Na}^{+}\right]$, the bigger the response. This could merely reflect the fact that subjects with higher baseline $\left[\mathrm{Na}^{+}\right]$ have less room for improvement, and likely reflect a lower degree of AVP activation. Furthermore, our study shows how baseline urine sodium has a negative association with $\left[\mathrm{Na}^{+}\right]$rise. This likely depends from a higher AVP activation leading to an elevated urine sodium, that might have necessitated higher doses of Tolvaptan for the same effect to take place, and is in line with the competitive nature of the AVP antagonism exerted by the drug. The positive correlation with $\mathrm{ScvO} 2$ might mean that patients with a relatively more increased body water pool tend to have a bigger response. Eventually, the negative correlation with BUN, as already seen with intravenous Conivaptan [33], likely depends on the fact that hypouraemia is a known feature of SIAD [46] (decreased proximal tubular reabsorption of urea and increased GFR resulting from expansion of body water pool [47]). One could speculate that subjects with the lowest BUN levels carry the largest increase in whole body water content, greatest extracellular fluid expansion, highest GFR, lowest proximal tubular reabsorption, and greatest distal delivery of substrate, thereby making them more responsive to water diuresis.

\section{Study limitations}

Potential limitations of the present study include the small sample population in a heterogeneous population of critically ill patients and the lack of statistical power in detecting significant side effects or complications of unwarranted fast corrections of hyponatremia. However, we succeeded in testing our primary hypothesis, which showed a significant improvement in $\left[\mathrm{Na}^{+}\right]$without short-term negative effects in a real-life scenario. Secondly, as a single-center study with no control group for comparison, the generalizability of the present results is limited. Moreover, given the observational nature of the study, the statistical associations between serum sodium concentration and outcome cannot be considered as causal relationship. Furthermore, factors correlated with sodium increase following Tolvaptan administration were evaluated using bivariate correlation; however, the reported factors might be either predictors of confounding factors not taken into account because of the limited sample size, which precluded any such correction. Larger prospective, placebo-controlled, randomized studies are needed to confirm the effects of Tolvaptan treatment as well as its cost-effectiveness. Finally, the long-term effects of low-dose Tolvaptan in this population were not tested in the present study.

\section{Conclusions}

In conclusion, this is the first case series to suggest that enteral administration of oral Tolvaptan is an effective aquaretic for the treatment of hyponatremia with preserved total body sodium pool in a heterogeneous cohort of critically ill patients. Further prospective well-designed studies are required to determine if the administration of Tolvaptan to critically ill hyponatremic patients can improve their clinical outcome.

\section{Additional file}

Additional file 1. Table S1. Baseline characteristics and primary and secondary outcomes in patients receiving either 7.5 or 15 mg of Tolvaptan. Table S2. Changes in electrolytes, hemodynamic and biochemistry parameters before and after administration of Tolvaptan in patients receiving either 7.5 or $15 \mathrm{mg}$.

\section{Abbreviations}

ICU: intensive care unit; BUN: blood urea nitrogen; AVP: arginine vasopressin; SIAD: syndrome of inappropriate antidiuresis; GFR: glomerular filtration rate; $\left[\mathrm{Na}^{+}\right]$: serum sodium concentration. 


\section{Authors' contributions}

MU had full access to all of the data in the study and takes responsibility for the integrity of the data and the accuracy of the data analysis, including and especially any adverse effects. MU and GI designed the study and wrote the first draft; $M U, E M, G M$, and Gl contributed substantially to the data analysis and interpretation, and the writing of the manuscript; $P F, C C, D O, M T$, and $A P$ performed the literature search, enrolled patients and recorded clinical data and revised the draft critically for important intellectual content. All authors read and approved the final manuscript.

\section{Author details}

1 Unità Operativa di Anestesia e Rianimazione, Azienda Ospedaliera San Paolo-Polo Universitario, Via A. Di Rudinì, 8, 20142 Milan, Italy. ${ }^{2}$ Dipartimento di Fisiopatologia Medico-Chirurgica e dei Trapianti, Università degli Studi di Milano, Milan, Italy.

\section{Acknowledgements}

This study was carried out with departmental funding only.

\section{Competing interests}

The authors declare that they have no competing interest.

Received: 23 June 2015 Accepted: 7 December 2015

Published online: 04 January 2016

\section{References}

1. Waikar SS, Mount DB, Curhan GC. Mortality after hospitalization with mild, moderate, and severe hyponatremia. Am J Med. 2009;122(9):857-65. doi:10.1016/j.amjmed.2009.01.027.

2. Bennani SL, Abouqal R, Zeggwagh AA, Madani N, Abidi K, Zekraoui A, et al. Incidence, causes and prognostic factors of hyponatremia in intensive care. Rev Med Interne. 2003;24(4):224-9.

3. Funk GC, Lindner G, Druml W, Metnitz B, Schwarz C, Bauer P, et al. Incidence and prognosis of dysnatremias present on ICU admission. Intensive Care Med. 2010;36(2):304-11. doi:10.1007/s00134-009-1692-0.

4. Stelfox HT, Ahmed SB, Khandwala F, Zygun D, Shahpori R, Laupland $\mathrm{K}$. The epidemiology of intensive care unit-acquired hyponatraemia and hypernatraemia in medical-surgical intensive care units. Crit Care. 2008;12(6):R162. doi:10.1186/cc7162.

5. Greenberg A, Verbalis JG, Amin AN, Burst VR, Chiodo JA 3rd, Chiong JR, et al. Current treatment practice and outcomes. Report of the hyponatremia registry. Kidney Int. 2015;88(1):167-77. doi:10.1038/ki.2015.4.

6. Sterns RH. Disorders of plasma sodium-causes, consequences, and correction. N Engl J Med. 2015;372(1):55-65. doi:10.1056/NEJMra1404489.

7. Robertson GL. Regulation of arginine vasopressin in the syndrome of inappropriate antidiuresis. Am J Med. 2006;119(7 Suppl 1):S36-42. doi:10.1016/j.amjmed.2006.05.006

8. Adler SM, Verbalis JG. Disorders of body water homeostasis in critical illness. Endocrinol Metab Clin North Am. 2006;35(4):873-94. doi:10.1016/j. ecl.2006.09.011

9. Schrier RW, Berl T. Nonosmolar factors affecting renal water excretion (first of two parts). N Engl J Med. 1975;292(2):81-8. doi:10.1056/ NEJM197501092920207.

10. Palm C, Pistrosch F, Herbrig K, Gross P. Vasopressin antagonists as aquaretic agents for the treatment of hyponatremia. Am J Med. 2006;119(7 Suppl 1):S87-92. doi:10.1016/j.amjmed.2006.05.014.

11. Verbalis JG, Goldsmith SR, Greenberg A, Korzelius C, Schrier RW, Sterns $\mathrm{RH}$, et al. Diagnosis, evaluation, and treatment of hyponatremia: expert panel recommendations. Am J Med. 2013;126(10 Suppl 1):S1-42. doi:10.1016/j.amjmed.2013.07.006.

12. Decaux G, Unger J, Brimioulle S, Mockel J. Hyponatremia in the syndrome of inappropriate secretion of antidiuretic hormone. Rapid correction with urea, sodium chloride, and water restriction therapy. JAMA. 1982;247(4):471-4.

13. Hantman D, Rossier B, Zohlman R, Schrier R. Rapid correction of hyponatremia in the syndrome of inappropriate secretion of antidiuretic hormone. An alternative treatment to hypertonic saline. Ann Intern Med. 1973;78(6):870-5.
14. Cherrill DA, Stote RM, Birge JR, Singer I. Demeclocycline treatment in the syndrome of inappropriate antidiuretic hormone secretion. Ann Intern Med. 1975;83(5):654-6.

15. Decaux G, Unger J, Mockel J. Urea therapy for inappropriate antidiuretic hormone secretion from tuberculous meningitis. JAMA. 1980;244(6):589-90.

16. Soupart A, Decaux G. Therapeutic recommendations for management of severe hyponatremia: current concepts on pathogenesis and prevention of neurologic complications. Clin Nephrol. 1996;46(3):149-69.

17. Jaber BL, Almarzouqi L, Borgi L, Seabra SF, Balk EM, Madias NE. Shortterm efficacy and safety of vasopressin receptor antagonists for treatment of hyponatremia. Am J Med. 2011;124(10):977. doi:10.1016/j. amjmed.2011.04.028 (e1-9)

18. Decaux $G$, Waterlot $Y$, Genette F, Hallemans R, Demanet JC. Inappropriate secretion of antidiuretic hormone treated with frusemide. Br Med J (Clin Res Ed). 1982;285(6335):89-90.

19. Greenberg A. Diuretic complications. Am J Med Sci. 2000;319(1):10-24.

20. Zietse R, van der Lubbe N, Hoorn EJ. Current and future treatment options in SIADH. NDT plus. 2009;2(Suppl_3):iii12-9. doi:10.1093/ndtplus/ sfp154.

21. Decaux G, Andres C, Gankam Kengne F, Soupart A. Treatment of euvolemic hyponatremia in the intensive care unit by urea. Crit Care. 2010;14(5):R184. doi:10.1186/cc9292.

22. Berl T. Vasopressin antagonists. N Engl J Med. 2015;372(23):2207-16. doi:10.1056/NEJMra1403672.

23. Imamura T, Kinugawa K, Minatsuki S, Muraoka H, Kato N, Inaba T, et al. Urine sodium excretion after tolvaptan administration is dependent upon baseline serum sodium levels: a possible explanation for the improvement of hyponatremia with scarce chance of hypernatremia by a vasopressin receptor antagonist. Int Heart J. 2014;55(2):131-7.

24. Schrier RW, Gross P, Gheorghiade M, Berl T, Verbalis JG, Czerwiec FS, et al. Tolvaptan, a selective oral vasopressin V2-receptor antagonist, for hyponatremia. N Engl J Med. 2006;355(20):2099-112. doi:10.1056/ NEJMoa065181.

25. Cyr PL, Slawsky KA, Olchanski N, Krasa HB, Goss TF, Zimmer C, et al. Effect of serum sodium concentration and tolvaptan treatment on length of hospitalization in patients with heart failure. Am J Health Syst Pharm. 2011;68(4):328-33. doi:10.2146/ajhp100217.

26. Gheorghiade M, Konstam MA, Burnett JC Jr, Grinfeld L, Maggioni AP, Swedberg K, et al. Short-term clinical effects of tolvaptan, an oral vasopressin antagonist, in patients hospitalized for heart failure: the EVEREST Clinical Status Trials. JAMA. 2007;297(12):1332-43. doi:10.1001/ jama.297.12.1332.

27. Rozen-Zvi B, Yahav D, Gheorghiade M, Korzets A, Leibovici L, Gafter U. Vasopressin receptor antagonists for the treatment of hyponatremia: systematic review and meta-analysis. Am J Kidney Dis. 2010;56(2):325-37. doi:10.1053/j.ajkd.2010.01.013.

28. Verrua E, Mantovani G, Ferrante E, Noto A, Sala E, Malchiodi E, et al. Severe water intoxication secondary to the concomitant intake of non-steroidal anti-inflammatory drugs and desmopressin: a case report and review of the literature. Hormones (Athens). 2013;12(1):135-41.

29. Mantovani E, Pirrone M, Spanu P, Albicini M, Gandola A, Ottolina D, et al. Hypo-osmolar fluid absorption in endoscopic resection: a new pharmacological approach. Minerva Anestesiol. 2015;81(5):591-2.

30. Bartter FC, Schwartz WB. The syndrome of inappropriate secretion of antidiuretic hormone. Am J Med. 1967;42(5):790-806.

31. Verbalis JG, Zeltser D, Smith N, Barve A, Andoh M. Assessment of the efficacy and safety of intravenous conivaptan in patients with euvolaemic hyponatraemia: subgroup analysis of a randomized, controlled study. Clin Endocrinol. 2008;69(1):159-68. doi:10.1111/j.1365-2265.2007.03149.x.

32. Zeltser D, Rosansky S, van Rensburg H, Verbalis JG, Smith N. Assessment of the efficacy and safety of intravenous conivaptan in euvolemic and hypervolemic hyponatremia. Am J Nephrol. 2007;27(5):447-57. doi:10.1159/000106456.

33. Velez JC, Dopson SJ, Sanders DS, Delay TA, Arthur JM. Intravenous conivaptan for the treatment of hyponatraemia caused by the syndrome of inappropriate secretion of antidiuretic hormone in hospitalized patients: a single-centre experience. Nephrol Dial Transplant. 2010;25(5):1524-31. doi:10.1093/ndt/gfp731. 
34. Nguyen MK, Kurtz I. Derivation of a new formula for calculating urinary electrolyte-free water clearance based on the Edelman equation. Am J Physiol Renal Physiol. 2005;288(1):F1-7. doi:10.1152/ajprenal.00259.2004.

35. Hall JE. Guyton and Hall Textbook of Medical Physiology. 12th ed. Philadelphia: Saunders; 2011.

36. Haussinger D, Roth E, Lang F, Gerok W. Cellular hydration state: an important determinant of protein catabolism in health and disease. Lancet. 1993;341(8856):1330-2.

37. Wald R, Jaber BL, Price LL, Upadhyay A, Madias NE. Impact of hospitalassociated hyponatremia on selected outcomes. Arch Intern Med. 2010;170(3):294-302. doi:10.1001/archinternmed.2009.513.

38. Friedman B, Cirulli J. Hyponatremia in critical care patients: frequency, outcome, characteristics, and treatment with the vasopressin V2-receptor antagonist tolvaptan. J Crit Care. 2013;28(2):219. doi:10.1016/j. jerc.2012.06.001 (e1-12).

39. Dasta JF, Chiong JR, Christian R, Lin J. Evaluation of costs associated with tolvaptan-mediated hospital length of stay reduction among US patients with the syndrome of inappropriate antidiuretic hormone secretion, based on SALT-1 and SALT-2 trials. Hosp Pract (1995). 2012;40(1):7-14. doi:10.3810/hp.2012.02.942

40. Naidech AM, Paparello J, Liebling SM, Bassin SL, Levasseur K, Alberts MJ, et al. Use of Conivaptan (Vaprisol) for hyponatremic neuro-ICU patients. Neurocrit Care. 2010;13(1):57-61. doi:10.1007/s12028-010-9379-5.
41. Galton C, Deem S, Yanez ND, Souter M, Chesnut R, Dagal A, et al. Open-label randomized trial of the safety and efficacy of a single dose conivaptan to raise serum sodium in patients with traumatic brain injury. Neurocrit Care. 2011;14(3):354-60. doi:10.1007/s12028-011-9525-8.

42. lapichino G. Low hemoglobin level with low oncotic pressure in critically ill patients. Is it a safe strategy?. Minerva Anestesiol. 2015.

43. Iapichino G, Pesenti A, Radrizzani D, Solca M, Pelizzola A, Gattinoni L. Nutritional support to long-term anesthetized and curarized patients under extracorporeal respiratory assist for terminal pulmonary failure. JPEN J Parenter Enteral Nutr. 1983;7(1):50-4.

44. Mistraletti G, Sabbatini G, Taverna M, Figini MA, Umbrello M, Magni P, et al. Pharmacokinetics of orally administered melatonin in critically ill patients. J Pineal Res. 2010;48(2):142-7. doi:10.1111/j.1600-079X.2009.00737.x.

45. Metzger BL, DeVita MV, Michelis MF. Observations regarding the use of the aquaretic agent conivaptan for treatment of hyponatremia. Int Urol Nephrol. 2008;40(3):725-30. doi:10.1007/s11255-008-9353-8.

46. Decaux G, Genette F, Mockel J. Hypouremia in the syndrome of inappropriate secretion of antidiuretic hormone. Ann Intern Med. 1980;93(5):716-7.

47. Verbalis JG. Pathogenesis of hyponatremia in an experimental model of the syndrome of inappropriate antidiuresis. Am J physiol. 1994;267(6 Pt 2):R1617-25.

\section{Submit your manuscript to a SpringerOpen ${ }^{\odot}$ journal and benefit from:}

- Convenient online submission

- Rigorous peer review

- Immediate publication on acceptance

- Open access: articles freely available online

- High visibility within the field

- Retaining the copyright to your article

Submit your next manuscript at springeropen.com 